\title{
ERRATUM
}

\section{Ideal rather than actual body weight should be used to calculate cell dose in allogeneic hematopoietic stem cell transplantation}

S Singhal, LI Gordon, MS Tallman, JN Winter, AO Evens, O Frankfurt, SF Williams, D Grinblatt,

L Kaminer, R Meagher and J Mehta

Bone Marrow Transplantation (2006) 37, 1067. doi:10.1038/sj.bmt.1705361

Correction to: Bone Marrow Transplantation (2006) 37, 553-557. doi:10.1038/sj.bmt.1705282; published online 30 January 2006

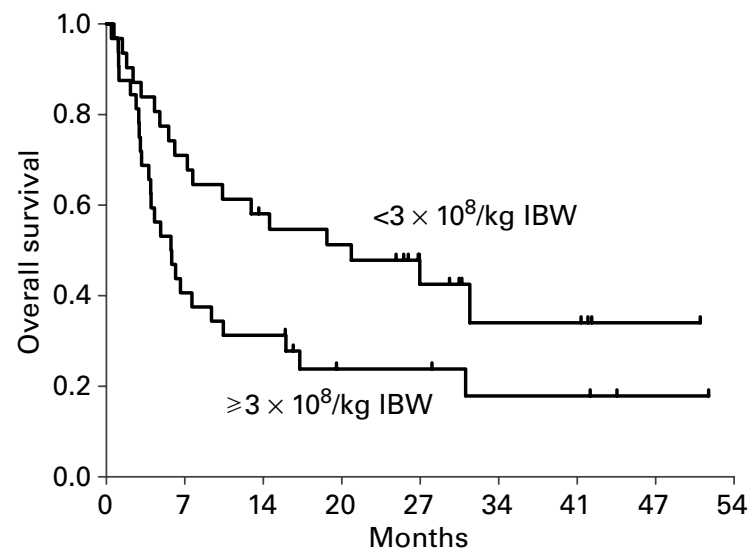

Figure 3 The effect of the $\mathrm{CD} 3+$ cell dose based on ideal body weight on overall survival $(P=0.032)$.
Due to a typesetting error the figure legends of Figures 3 and 4 were published incorrectly. The figures with corrected legends are shown below.

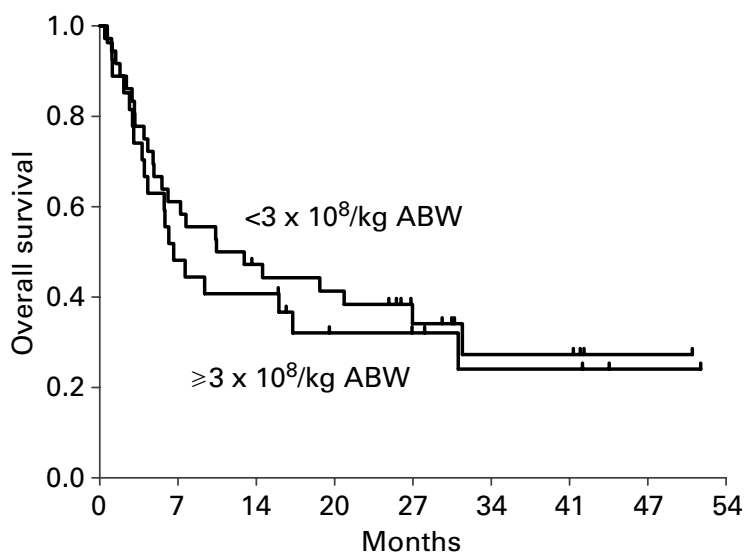

Figure 4 The effect of the CD3 + cell dose based on ideal body weight on overall survival $(P=0.56)$. 